\title{
Avanços Tecnológicos e Velhos Problemas Ambientais
}

Technological Advances and old Environmental Problems

Avances Tecnológicos y Viejos Problemas Ambientales

Divanise Suruagy Correia ${ }^{1}$

Neste último número de 2018, apresentamos temas relacionados ao meio ambiente, ao ensino e ao fenômeno da violência entre idosos, ao tempo em que também informamos que passamos a receber um grande incentivo, com a aprovação de nossa proposta em Edital de Apoio à Editoração e Publicação de Periódicos Científicos da Fundação de Amparo à Pesquisa do Estado de Alagoas (FAPEAL).

A água é um recurso natural importante para a vida humana e ocupa aproximadamente $70 \%$ da superfície sendo $97 \%$ dela salgada. A quantidade de água necessária para $\mathrm{O}$ desenvolvimento das atividades humanas vem crescendo nos últimos tempos no Brasil, todavia a quantidade de água potável não aumentou. A preservação dessas águas ocorre através do saneamento básico, tema que é discutido no artigo Vigilância ambiental em saúde: análise do fornecimento, controle e qualidade da água para consumo humano no estado de Alagoas.

Os recursos da Tecnologia de Informação e Comunicação vem apoiando o modelo de ensino não presencial que cresce no Brasil. Este modelo de ensino/aprendizagem utiliza o ambiente virtual, onde o processo de aprendizagem ocorre através de conteúdos disponibilizados por um professor que se coloca à distância, aparecendo a Internet como meio de comunicação. Diante da extensão do

${ }^{1}$ Professora associada da Faculdade de Medicina da Universidade Federal de Alagoas. Autora correspondente: Campus A. C. Simões. Av. Lourival Melo Mota, s/n. Tabuleiro dos Martins. 57072-900. Maceió, Al, Brasil. E-mail: divanisesuruagy@gmail.com

Recebido: Ago/2018 - Aceito: Dez./2018. 
território brasileiro este modelo representa uma oportunidade de difusão do conhecimento aos locais distantes e desprovidos de maiores condições e desenvolvimento. $\mathrm{O}$ artigo intitulado: Encontros, confrontos e possibilidades do e-Learning na Educação Permanente em Saúde de Alagoas debate este tema apresentando experiência no estado de Alagoas.

O diagnóstico precoce atua como prevenção nos casos de lesões do colo uterino no tocante ao câncer de colo que é causa de morbimortalidade feminina sendo a "quarta causa de morte de mulheres por câncer no Brasil”. É reconhecido papel do vírus HPV no aparecimento deste tipo de câncer sendo a colposcopia uma forma de detecção de lesões associada a colpocitologia, questão discutida no artigo intitulado: Lesões no colo uterino sob visão colposcópica: achados anatomopatológicos em serviço ginecológico.

$O$ ensino na Universidade se sustenta na indissociabilidade das atividades de ensino, pesquisa $\mathrm{e}$ extensão, havendo importância e igualdade entre as mesmas.

Todavia ainda se produz um conhecimento desligado das necessidades populares cotidianas, sendo o conhecimento universitário do século passado $\mathrm{XX}$, um conhecimento predominantemente disciplinar. A função acadêmica da Extensão abre uma campo de possibilidades mas também revela entraves e dificuldades a serem enfrentados em sua implementação. Atualmente as DCNs dos curso da saúde trazem a necessidade de se promover a curricularização da extensão nos cursos superiores, estratégias que estão sendo discutidas. Neste número trazemos dois artigos que se referem e discutem a extensão: "A extensão universitária e a promoção da saúde no Brasil: revisão sistemática" e "Ligas acadêmicas no Brasil: revisão crítica de adequação às Diretrizes Curriculares Nacionais", que contribuirão na discussão do tema.

Em 1956 começava um projeto com o intuito de "ajudar os povos dos países em desenvolvimento", iniciativa de um presidente americano. O hospital HOPE montado em um navio foi uma iniciativa da fundação "The People-toPeople Health Foundation Inc" (Fundação de Saúde do Povo para o Povo), de Wisconsin, Washington, EUA. O navio-escola contava com 140 professores de várias especialidades da Medicina, Odontologia e Enfermagem e possuía 108 leitos, equipamentos para diagnósticos e cirurgias, salas de aula, oficina de consertos e reparos, estação 
de rádio, bar, padaria, açougue, barbearia, além de cinema, igrejas, salões de refeições e de recreação. Em 1970 aporta no Nordeste brasileiro e mantem contato com universidades federais no sentindo de programa de intercâmbio científico. Docentes enfermeiras alagoanas que vivenciaram sua estada em Alagoas publicam o livro: “O Navio Hope: Um Novo Encontro Entre a Enfermagem Brasileira e a Norte-americana" que cuja resenha é apresentada neste número no artigo: "O Progresso da Enfermagem Alagoana".

A população mundial está em processo de envelhecimento e neste contexto encontra-se também a população brasileira. A associada a este processo de envelhecimento vemos também o aumento da violência entre esta faixa etária, tema que é discutido no artigo: Prevalência de violência e relação com apoio social e sintomas depressivos em idosos de Natal, Rio Grande do Norte, Brasil".

Esperamos que nossos leitores e autores apreciem os temas aqui abordados aguardando-os novamente em 2019. 